\title{
Interactive comment on "CALIOPE-Urban v1.0: Coupling R-LINE with a mesoscale air quality modelling system for urban air quality forecasts over Barcelona city (Spain)" by Jaime Benavides
} et al.

Jaime Benavides et al.

jaime.benavides@bsc.es

Received and published: 28 May 2019

The authors wish to thank anonymous reviewer \#1 for his/her valuable comments and suggestions. Find in attachment the supplement with the responses to the reviewer's comments.

Please also note the supplement to this comment: https://www.geosci-model-dev-discuss.net/gmd-2019-48/gmd-2019-48-AC1supplement.pdf 
Interactive comment on Geosci. Model Dev. Discuss., https://doi.org/10.5194/gmd-2019-48, 2019.
GMDD

Interactive

comment 